\title{
Bibliografia publikacji ks. dr. hab. Jana Szymczyka, prof. KUL
}

1986

Reinhold Schneider - myśliciel również na dziś, „Niedziela” 1986, nr 47, s. 5, 7.

1989

W imieniu dziecka poczętego - refleksje wokół życia, „Gazeta Radomska” II Jednodniówka z 28.05.1989, s. 4.

Posługa słowa i modlitwy - społeczne nauczanie ks. Romana Kotlarza w kontekście „wydarzeń radomskich”, „Biuletyn Kwartalny Radomskiego Towarzystwa Naukowego" 1990, t. 27, z. 1-2, s. 85-97.

* Dr Monika Dobrogowska - Katedra Socjologii Struktur, Procesów Społecznych i Pracy Socjalnej, Instytut Nauk Socjologicznych, Wydział Nauk Społecznych, Katolicki Uniwersytet Lubelski Jana Pawła II, e-mail: monika.dobrogowska@kul.pl, ORCID: 0000-0002-1219-3546.

** Ks. mgr Marek Pabich - Katedra Socjologii Struktur, Procesów Społecznych i Pracy Socjalnej, Instytut Nauk Socjologicznych, Wydział Nauk Społecznych, e-mail: marek.pabich@kul.pl, ORCID: 0000-0001-5358-0051. 
Patrząc na ten świat..., [b.w.], Radom 1991, ss. 171.

Konstanty Świdziński. Życie i działalność, Radom 1991 (broszura).

Św. Augustyn - „niespokojne serce” [rec.: S. Kowalczyk, Człowiek i Bóg w nauce św. Augustyna, ODiSS, Warszawa 1987, ss. 276], w: J. Szymczyk, Patrzac na ten świat..., [b.w.], Radom 1991, s. 140-143.

W oczekiwaniu na Ojca Świętego. Śladami Karola Wojtyly, „Ziemia Radomska” 1991, nr 16, s. 1.

„Wczoraj” i „dziś” Diecezji, „Ziemia Radomska” 1991 (wyd. specjalne), s. 6.

Kościół a liberalizm, „Ład” 1991, R. 9, nr 38, s. 1, 7.

Przed wyborami..., „Słowo Powszechne” 1991, nr 234, s. 1-2.

\section{2}

Chrześcijańska koncepcja państwa, „Ład” 1992, R. 10, nr 6, s. 1.

Etyka mass mediów, „Ład” 1992, R. 10, nr 20, s. 1.

Filozofia wolnego rynku, „Ład” 1992, R. 10, nr 3, s. 1, 7.

Pusta kiesa, „Gazeta Lokalna” [dodatek do „Gazety Wyborczej”] 1992, nr 248, s. 1.

\section{3}

Filozof o Bogu [rec.: S. Kowalczyk, Filozofia Boga, Lublin 1993, ss. 325], „Chrześcijanin w Świecie" 1993, R. 23, nr 4, s. 151-154.

Jakie państwo: opiekuńcze czy pomocnicze?, „Chrześcijanin w Świecie” 1993, R. 23, nr 2, s. 209-230.

Katolickie Stowarzyszenie Dziennikarzy, „Ave” 1993, nr 5, s. 11. 
Uprawianie słowa, „Gazeta Lokalna” [dodatek do „Gazety Wyborczej”] 1993, nr 21, s. 3.

W stronę chadecji, „Ład” 1993, R. 11, nr 45, s. 1, 7.

Wymarła czy tylko zgorzkniała klasa?, „Dziennik Radomski” 1993, nr 60, s. 1, 4 [udział w dyskusji redakcyjnej].

\section{4}

Elementy zasady solidarności w nauczaniu społecznym Jana Pawła II, „Chrześcijanin w Świecie" 1994, R. 24, nr 2/3, s. 160-169.

Gmina, czyli wspólnota. Przed wyborami samorządowymi, „Ład” 1994, R. 12, nr 17, s. 1,4 .

O zasadzie pomocniczości, „Ład” 1994, R. 12, nr 8, s. 1, 4.

\section{6}

Nowe dzieło o człowieku, [rec.: S. Kowalczyk, Człowiek, społeczność, wartości. $Z$ refleksji nad człowiekiem, Lublin 1995], „Zeszyty Sandomierskie. Biuletyn Towarzystwa Naukowego Sandomierskiego" 1996, nr 4, s. 62-63.

[Rec.: S. Kowalczyk, Filozofia kultury. Próba personalistycznego ujęcia problematyki, Lublin 1996, ss. 218], „Społeczeństwo” 1996, R. 6, nr 4, s. 757-760.

Zasada dobra wspólnego w ujęciu przedstawicieli Szkoły Lubelskiej. (Prezentacja rozprawy doktorskiej), „Kronika Diecezji Radomskiej” 1996, R. 5, nr 2-3, s. 297-298.

Student się pożali, kapłan wysłucha i może pocieszy... „Życie Radomskie” 1996, nr 17, s. 2.

\section{7}

Księga pamiatkowa ku czci prof. dra hab. Adama Rodzińskiego, „Roczniki Nauk Społecznych" 1997, t. 25, nr 1, ss. 327 (współredaktor zeszytu wraz ze Stanisławem Kowalczykiem). 
The Lublin School Representatives' Approach to the Normative Character of the Common Good, w: Ku prawdzie we wspólnocie człowieka i Boga. Studia dedykowane ks. Stanisławowi Kowalczykowi, red. E. Balawajder, P. Nitecki, A. Jabłoński, Wydawnictwo Diecezjalne, Sandomierz 1997, s. 289-300.

Dobro osoby a dobro wspólne, „Zeszyty Społeczne KIK” 1997, R. 5, nr 5, s. 18-20.

Pojęcie zasady społecznej w kontekście dobra wspólnego w ujęciu przedstawicieli szkoły lubelskiej, „Roczniki Nauk Społecznych” 1997, t. 25, nr 1, s. 111-124.

[Rec.: S. Kowalczyk, Filozofia kultury. Próba personalistycznego ujęcia problematyki, Lublin 1996, ss. 218], „Zeszyty Naukowe KUL” 1997, t. 40, nr 1-2, s. 214-218.

Bibliografia prac naukowych prof. dra hab. Adama Rodzińskiego, „Roczniki Nauk Społecznych 1997, t. 25, nr 1, s. 27-32.

Potrójny jubileusz, „Mikrus dziennikarski” 1997, R. 4, nr 4, s. 91-93.

\section{8}

Immanentny i instrumentalny aspekt dobra wspólnego, „Roczniki Nauk Społecznych" 1998, t. 26, nr 1, s. 157-170.

O nowa jakość kultury, „Zeszyty Społeczne KIK” 1998, R. 6, nr 6, s. 30-32.

Ks. prof. Stanisław Kowalczyk, 65 „wiosen życia”, 40-lecie profesury, 35 lat pracy w KUL, „Przegląd Uniwersytecki” 1998, R. 10, nr 1, s. 12.

Jubileusz profesora Adama Rodzińskiego, „Przegląd Uniwersytecki” 1998, R. 10, nr 6, s. 14, 27.

Potrójny jubileusz, „Zeszyty Społeczne KIK” 1998, R. 6, nr 6, s. 27.

\section{9}

Hierarchiczny charakter dobra wspólnego w ujęciu przedstawicieli szkoły lubelskiej, „Roczniki Nauk Społecznych” 1999, t. 27, nr 1, s. 33-49. 
Człowiek istota otwarta na Boga, w: Wyznawać wiarę dzisiaj, red. S. Łabendowicz, Wydawnictwo Diecezjalne, Sandomierz 1999, s. 25-30.

Dobro wspólne a prawa człowieka w ujęciu przedstawicieli lubelskiej szkoły katolickiej nauki społecznej, w: Pomiędzy etyka a polityka. 80 lat socjologii w Katolickim Uniwersytecie Lubelskim (1918-1998), red. E. Hałas, TN KUL, Lublin 1999, s. 277-297.

Kościół a państwo, „Zeszyty Społeczne KIK” 1999, R. 7, nr 7, s. 30-31.

\section{0}

Mass media a rzeczywistość społeczna, „Zeszyty Społeczne KIK” 2000, R. 8, nr 8, s. 43-49.

\section{1}

Rozumienie wartości w pismach Stanisława Ossowskiego, „Summarium” 2001/2002, R. 30/31, s. 53-73.

Koncepcja ładu porozumień międzygrupowych w ujęciu Stanisława Ossowskiego, „Zeszyty Społeczne KIK” 2001, R. 9, nr 9, s. 149-158.

\section{2}

Elementy zasady równości społecznej, „Zeszyty Społeczne KIK” 2002, R. 10, nr 10, s. 99-108.

Uwarunkowania współczesnej polskiej socjologii, „Studia Diecezji Radomskiej” 2002 , t. 4 , s. 355-364.

Podstawy ładu społecznego w pismach Czesława Strzeszewskiego, w: Czesław Strzeszewski. Współtwórca i świadek katolicyzmu społecznego w Polsce w XX wieku. Ksiega pamiątkowa, red. E. Balawajder, TN KUL, Lublin 2002, s. 113-130.

[Rec.: E. Balawajder, Wojciech Korfanty. Myśl katolicko-społeczna i działalność, Księgarnia św. Jacka, Katowice 2001, ss. 360], „Zeszyty Społeczne KIK” 2002, R. 10, nr 10, s. 237-239. 
Ks. dr Jan Szymczyk wspomina..., [wywiad przeprowadziły J. Jurgowska i J. Srokol], „Socpresska” 2002, nr 3, s. 3.

Aksjologiczno-socjologiczne elementy sztuki w pismach Stanisława Ossowskiego, „Kultura i Społeczeństwo” 2003, nr 2, s. 51-70.

Myśl społeczno-polityczna eurazjatyzmu, „Zeszyty Społeczne KIK” 2003, R. 11, nr 11, s. 123-132.

[Rec.: A. Jabłoński, Status teoretyczny i funkcja techniczna wiedzy o społeczeństwie. Wokół myśli Karla R. Poppera i Józefa M. Bocheńskiego, TN KUL, Lublin 2002, ss. 261], „Zeszyty Społeczne KIK” 2003, R. 11, nr 11, s. 232-234.

\section{4}

Odkrywanie wartości. Z problematyki socjologiczno-aksjologicznej, Polihymnia, Lublin 2004, ss. 261.

Filozofia pochylona nad człowiekiem. Studia dedykowane Księdzu Profesorowi Stanisławowi Kowalczykowi, red. E. Balawajder, A. Jabłoński, J. Szymczyk, TN KUL, Lublin 2004, ss. 735.

Dylematy współczesnej socjologii polskiej, „Zeszyty Społeczne KIK” 2004, R. 12, nr 12, s. 139-148.

Kategoria narodu - wyzwaniem dla badaczy życia społecznego, w: Filozofia pochylona nad człowiekiem. Studia dedykowane Księdzu Profesorowi Stanisławowi Kowalczykowi, red. E. Balawajder, A. Jabłoński, J. Szymczyk, TN KUL, Lublin 2004, s. 397-408.

Pojęcie dziedzictwa kulturowego w pismach Stanisława Ossowskiego, w: Koncepcje socjologiczne Stanisława Ossowskiego a teoretyczne i praktyczne zagadnienia współczesności. Materiały z konferencji naukowej w Zielonej Górze 20-21.10.2003 r., red. M. Chałubiński, J. Goćkowski, I. Kaczmarek-Murzyniec, A. Woźniak, Toruń 2004, s. 241-263. 
Wykaz prac doktorskich i magisterskich pisanych pod kierunkiem ks. prof. dra hab. Stanisława Kowalczyka, w: Filozofia pochylona nad człowiekiem. Studia dedykowane księdzu profesorowi Stanisławowi Kowalczykowi, red. E. Balawajder, A. Jabłoński, J. Szymczyk, TN KUL, Lublin 2004, s. 95-103.

\section{5}

Pomiędzy marzeniami a faktami. Szkice socjologiczne, Norbertinum, Lublin 2005, ss. 170.

W świecie ludzkich kreacji. Stanisława Ossowskiego koncepcja rzeczywistości społecznej, Wydawnictwo KUL, Lublin 2005, ss. 506.

Wartości a system społeczno-kulturowy. Szkic socjologiczny, „Studia Catholica Podoliae" 2005, R. 4, nr 4, s. 155-174.

$Z$ ks. dr. Janem Szymczykiem o jego najnowszej książce [rozmawiała M. Dobrogowska], „Socpresska” 2005, nr 2, s. 6-7.

\section{6}

W stronę internalizacji demokracji partycypacyjno-deliberatywnej, „Universitas Gedanensis" 2006, R. 18, nr 1, s. 100-112.

Mannheim Karl, w: Encyklopedia katolicka, t. 11, red. E. Ziemann, TN KUL, Lublin 2006, kol. 1170-1172.

Oligarchia, w: Powszechna encyklopedia filozofii, t. 7, red. A. Maryniarczyk i in., Polskie Towarzystwo Tomasza z Akwinu, Lublin 2006, s. 790-792.

\section{7}

Idea wolności a partycypacja w życiu społecznym w ujęciu Stanisława Ossowskiego, w: Społeczeństwo obywatelskie. Modele teoretyczne a praktyka społeczna, red. E. Balawajder, Wydawnictwo KUL, Lublin 2007, s. 325-347. 
Socjologiczno-aksjologiczne elementy „Laborem exercens”, w: Praca kluczem polityki społecznej. Materiały sympozjum w 25-lecie wydania encykliki „Laborem exercens" Jana Pawła II, red. J. Mazur, TN KUL, Lublin 2007, s. 43-60.

[Rec.: S. Kowalczyk, Człowiek w poszukiwaniu wartości. Elementy aksjologii personalistycznej, Wyd. KUL, Lublin 2011, ss. 208], „Roczniki Nauk Społecznych” 2007 , t. 35, nr 1, s. 145-149.

\section{8}

Fenomen więzi społecznej w ujęciu Stanisława Ossowskiego, „Zeszyty Naukowe KUL” 2008, t. 51, nr 1, s. 19-33.

Między wolnością a tendencjami uniformizacyjnymi. $Z$ problematyki funkcjonowania mass mediów w demokracji, w: Między unifikacją a dezintegracją. Kondycja wiedzy we wspótczesnym społeczeństwie, red. A. Jabłoński, M. Zemło, Wydawnictwo KUL, Lublin 2008, s. 255-271.

\section{9}

Wiedza - władza, red. A. Jabłoński, M. Zemło, J. Szymczyk, Wydawnictwo KUL, Lublin 2009, ss. 355.

Elementy interakcji: media lokalne a władza samorzadowa, w: Społeczeństwo, przestrzeń, rodzina. Księga jubileuszowa dedykowana profesorowi Piotrowi Kryczce, red. M. Szyszka, Wydawnictwo KUL, Lublin 2009, s. 201-212.

Katedra Socjologii Makrostruktur i Ruchów Społecznych. W stronę realizacji zasady komplementarności, w: Tradycja i współczesność. 90 lat socjologii w Katolickim Uniwersytecie Lubelskim, red. S. Fel, J.P. Gałkowski, J.M. Zabielska, Wydawnictwo KUL, Lublin 2009, s. 145-151.

Wokół relacjonistycznego rozumienia władzy, w: Wiedza - władza, red. A. Jabłoński, J. Szymczyk, M. Zemło, Wydawnictwo KUL, Lublin 2009, s. 51-66. 


\section{0}

Wartości - interesy - struktury społeczne. Uwarunkowania ludzkiej kreatywności i partycypacji w życiu publicznym, red. J. Szymczyk, Norbertinum, Lublin 2010, ss. 254.

Wiedza między słowem a obrazem, red. A. Jabłoński, M. Zemło, J. Szymczyk, Wydawnictwo KUL, Lublin 2010, ss. 542.

Wokót wartości i więzi społecznych Polaków. Wybrane aspekty i tendencje, „Zeszyty Naukowe KUL” 2010, t. 53, nr 4, s. 3-22.

Specyfika nowych ruchów społecznych, w: Wartości, interesy, struktury społeczne. Uwarunkowania ludzkiej kreatywności i partycypacji w życiu publicznym, red. J. Szymczyk, Norbertinum, Lublin 2010, s. 33-82.

Układy patronacko-klienckie w perspektywie społecznych uwarunkowań wiedzy: pomiędzy ogladami a obrazami, w: Wiedza między słowem a obrazem, red. A. Jabłoński, J. Szymczyk, M. Zemło, Wydawnictwo KUL, Lublin 2010, s. 283-298.

Zamiast wprowadzenia. O Katedrze Socjologii Makrostruktur i Ruchów Społecznych, w: Wartości - interesy - struktury społeczne. Uwarunkowania ludzkiej kreatywności i partycypacji w życiu publicznym, red. J. Szymczyk, Norbertinum, Lublin 2010, s. 5-15.

Parsons Talcot, w: Encyklopedia katolicka, t. 14, red. E. Gigilewicz, TN KUL, Lublin 2010, kol. 1376-1377.

\section{1}

Przemiany wartości i więzi we współczesnym społeczeństwie polskim, w: Odpowiedzialność społeczna w innowacyjnej gospodarce, red. P. Kawalec, A. Blachut, Wydawnictwo KUL, Lublin 2011, s. 299-319.

Mirek Franciszek, w: Encyklopedia filozofii polskiej, t. 2, red. A. Maryniarczyk $\mathrm{i}$ in., Polskie Towarzystwo Tomasza z Akwinu, Lublin 2011, s. 165-167. 


\section{2}

Segmenty aktywności społecznej a wartości. Idee i praktyka, red. J. Szymczyk, Wydawnictwo KUL, Lublin 2012, ss. 326.

Kontrowersje dyskursywne. Między wiedza specjalistyczna a praktyka społeczna, red. A. Jabłoński, J. Szymczyk, M. Zemło, Wydawnictwo KUL, Lublin 2012, ss. 526.

Tworzenie iluzji społecznych. Wiedza w sferze publicznej, red. A. Jabłoński, J. Szymczyk, M. Zemło, Wydawnictwo KUL, Lublin 2012, ss. 540.

Elementy kultury i sportu $z$ perspektywy aksjologii. W kręgu myśli Stanisława Kowalczyka, „Roczniki Nauk Społecznych” 2012, t. 4 (40), nr 1, s. 81-106.

Idea republikanizmu a think-tanki. Polskie realia, w: Kontrowersje dyskursywne. Między wiedza specjalistyczna a praktyką społeczną, red. A. Jabłoński, J. Szymczyk, M. Zemło, Wydawnictwo KUL, Lublin 2012, s. 197-220.

Rudymentarne wartości republikańskie. Zarys problematyki, w: Segmenty aktywności społecznej a wartości. Idee i praktyka, red. J. Szymczyk, Wydawnictwo KUL, Lublin 2012, s. 111-152.

Wartości a zachowania i działania społeczne, w: Segmenty aktywności społecznej a wartości. Idee i praktyka, red. J. Szymczyk, Wydawnictwo KUL, Lublin 2012, s. $9-35$.

Ruchy społeczne, w: Encyklopedia katolicka, t. 17, red. E. Gigilewicz, TN KUL, Lublin 2012, kol. 535-538.

\section{3}

Forms and Manifestations of the Power of Media, „Roczniki Nauk Społecznych” 2013 , t. 5 (41), nr 3, s. $165-176$.

Elementy socjologii ciała, w: Socjologia medycyny w multidyscyplinarnych badaniach humanizujacych biomedycynę, red. M. Skrzypek, Wydawnictwo KUL, Lublin 2013, s. 197-222.

Świadomość polityczna, w: Formy świadomości społecznej, red. K. Sztalt, M. Zemło, TN KUL, Lublin 2013, s. 317-343. 
Socjologia, w: Encyklopedia katolicka, t. 18, red. E. Gigilewicz, TN KUL, Lublin 2013, kol. 492-493.

Socjologia ciała, w: Encyklopedia katolicka, t. 18, red. E. Gigilewicz, TN KUL, Lublin 2013, kol. 504-505.

Socjologia edukacji, w: Encyklopedia katolicka, t. 18, red. E. Gigilewicz, TN KUL, Lublin 2013, kol. 507.

Socjologia ekonomiczna, w: Encyklopedia katolicka, t. 18, red. E. Gigilewicz, TN KUL, Lublin 2013, kol. 501-502.

Socjologia miasta, w: Encyklopedia katolicka, t. 18, red. E. Gigilewicz, TN KUL, Lublin 2013, kol. 500-501.

Socjologia narodu, w: Encyklopedia katolicka, t. 18, red. E. Gigilewicz, TN KUL, Lublin 2013, kol. 499.

Socjologia nauki, w: Encyklopedia katolicka, t. 18, red. E. Gigilewicz, TN KUL, Lublin 2013, kol. 508.

Socjologia organizacji, w: Encyklopedia katolicka, t. 18, red. E. Gigilewicz, TN KUL, Lublin 2013, kol. 502.

Socjologia polityki, w: Encyklopedia katolicka, t. 18, red. E. Gigilewicz, TN KUL, Lublin 2013, kol. 503.

Socjologia prawa, w: Encyklopedia katolicka, t. 18, red. E. Gigilewicz, TN KUL, Lublin 2013, kol. 503-504.

Socjologia rodziny, w: Encyklopedia katolicka, t. 18, red. E. Gigilewicz, TN KUL, Lublin 2013, kol. 494-495.

Socjologia ruchów społecznych, w: Encyklopedia katolicka, t. 18, red. E. Gigilewicz, TN KUL, Lublin 2013, kol. 502-503.

Socjologia sportu, w: Encyklopedia katolicka, t. 18, red. E. Gigilewicz, TN KUL, Lublin 2013, kol. 506.

Socjologia struktur społecznych, w: Encyklopedia katolicka, t. 18, red. E. Gigilewicz, TN KUL, Lublin 2013, kol. 493-494. 
Socjologia turystyki, w: Encyklopedia katolicka, t. 18, red. E. Gigilewicz, TN KUL, Lublin 2013, kol. 506-507.

Socjologia wiedzy, w: Encyklopedia katolicka, t. 18, red. E. Gigilewicz, TN KUL, Lublin 2013, kol. 507-508.

Socjologia wychowania, w: Encyklopedia katolicka, t. 18, red. E. Gigilewicz, TN KUL, Lublin 2013, kol. 495-496.

Społeczeństwo, w: Encyklopedia katolicka, t. 18, red. E. Gigilewicz, TN KUL, Lublin 2013, kol. 692-694.

Stratyfikacja społeczna, w: Encyklopedia katolicka, t. 18, red. E. Gigilewicz, TN KUL, Lublin 2013, kol. 1008-1010.

Struktury społeczne, w: Encyklopedia katolicka, t. 18, red. E. Gigilewicz, TN KUL, Lublin 2013, kol. 1050-1051.

\section{4}

Elements of the Application of the Complementarity Principle. Issues of the Sociology of Subjectivity and Social Structures, Wydawnictwo Adam Marszałek, Toruń 2014, ss. 287.

Wiedza a instytucjonalizacja nieodpowiedzialności, red. A. Jabłoński, J. Szymczyk, M. Zemło, Wydawnictwo KUL, Lublin 2014, ss. 388.

Elementy interdyscyplinarnej kooperacji socjologii ciała, sportu i turystyki, w: Podstawy interdyscyplinarności w naukach o zdrowiu. Poznawcza tożsamość dyscyplin badajacych socjokulturowy wymiar zdrowia i choroby, red. M. Skrzypek, Wydawnictwo KUL, Lublin 2014, s. 113-136.

Elementy ontologii społecznej w ujęciu Stanisława Ossowskiego, w: Ossowski z perspektywy pótwiecza, red. A. Sułek, Oficyna Naukowa, Instytut Socjologii Uniwersytetu Warszawskiego, Warszawa 2014, s. 15-51.

\section{5}

Aksjologia posługi słowa ks. Jerzego Popiełuszki, „Arcana” 2015, nr 123, s. 138-148. 
Kreowanie społeczeństwa niewiedzy, red. A. Jabłoński, J. Szymczyk, M. Zemło, Wydawnictwo KUL, Lublin 2015, ss. 532.

Błogosławiony ks. Jerzy Popiełuszko patronem jedności ruchu „Solidarnośc”, w: Obrońca prawdy. Materialy z konferencji: O prawdzie w życiu publicznym. błogosławiony ks. Jerzy Popiełuszko w 30. rocznice zbrodni, zorganizowanej przez Fundację Niepodległości i Instytut Europeistyki KUL Jana Pawła II 21 listopada 2014 r. oraz Błogosławiony ks. Jerzy Popiełuszko obrońca prawdy o człowieku, zorganizowanej przez KU NSZZ „Solidarność” KUL przy współudziale Katedry Pedagogiki Chrześcijańskiej KUL Jana Pawła II 14 kwietnia 2015 r., red. E. Różycka, Fundacja Niepodległości, Lublin [cop. 2015], s. 163-182.

Przemiany wartości Polaków. Wybrane aspekty i tendencje, w: Społeczne i etyczne aspekty rozwoju społecznego, red. W. Jedynak, J. Kinal, Wydawnictwo Uniwersytetu Rzeszowskiego, Rzeszów 2015, s. 7-34.

Ciało jako wartość, w: Leksykon socjologii moralności. Podstawy, teorie, badania, perspektywy, red. J. Mariański, Nomos, Kraków 2015, s. 79-86.

Socjologia ciała jako nauka, w: Leksykon socjologii moralności. Podstawy, teorie, badania, perspektywy, red. J. Mariański, Zakład Wydawniczy Nomos, Karków 2015, s. 721-726.

Sport i moralność, w: Leksykon socjologii moralności. Podstawy, teorie, badania, perspektywy, red. J. Mariański, Zakład Wydawniczy Nomos, Karków 2015, s. 787-792.

\section{6}

Zaufanie społeczne. Teoria - idee - praktyka, red. J. Szymczyk, Oficyna Naukowa, Warszawa 2016, ss. 476.

Intelektualiści. Między powołaniem a apostazja, red. A. Jabłoński, J. Szymczyk, M. Zemło, Wydawnictwo KUL, Lublin 2016, ss. 206.

O potrzebie wspólnoty dziś, „Arcana” 2016, nr 130, s. 5-15.

Dysfunkcjonalna recepcja wizerunku ciała człowieka i jej społeczne skutki, w: Na krawędzi. Reperkusje zachowań ryzykownych $w$ relacji do ciała, red. P. Prüfer, 
Wydawnictwo Naukowe Akademii im. Jakuba z Paradyża, Gorzów Wielkopolski 2016, s. 25-47.

Zamiast wprowadzenia. W stronę socjologii zaufania z perspektywy wartości, w: Zaufanie społeczne. Teoria - idee - praktyka, red. J. Szymczyk, Oficyna Naukowa, Warszawa 2016, s. 7-31.

Zaufanie a soma. Rola ciała człowieka w interakcjach społecznych, w: Zaufanie społeczne. Teoria - idee - praktyka, red. J. Szymczyk, Oficyna Naukowa, Warszawa 2016, 403-447.

Cielesność, kult ciała, w: Encyklopedia aksjologii pedagogicznej, red. K. Chałas, A. Maj, Polskie Wydawnictwo Encyklopedyczne, Radom 2016, s. 157-163.

\section{7}

Wiedza a moralność, red. A. Jabłoński, J. Szymczyk, M. Zemło, Wydawnictwo KUL, Lublin 2017, ss. 354.

\section{8}

Funkcje mowy ciała $w$ procesie kreowania wizerunku publicznego polityków, „Roczniki Nauk Społecznych” 2018, t. 10 (46), nr 2, s. 131-161.

Wokół (nie)odpowiedzialności: między PRL a III RP, „Arcana” 2018, nr 142, s. 22-33.

Aspekty i funkcje więzi społecznej. W kręgu myśli Jana Turowskiego, w: Jan Turowski (1917-2006). Myśl socjologiczna, red. M. Wódka, S. Fel, Wydawnictwo KUL, Lublin 2018, s. 57-84.

Elementy aktywności fizycznej. Socjologia ciała, sportu i turystyki, w: 100 lat socjologii w Katolickim Uniwersytecie Lubelskim Jana Pawła II. Idee, teorie, badania, red. W. Szymczak, TN KUL, Lublin 2018, s. 373-387.

Instytucje, procesy i systemy społeczne. Makrosocjologia, w: 100 lat socjologii w Katolickim Uniwersytecie Lubelskim Jana Pawła II. Idee, teorie, badania, red. W. Szymczak, TN KUL, Lublin 2018, s. 63-85. 
Socjologia partycypacji społecznej i Nowych Ruchów Społecznych, w: 100 lat socjologii w Katolickim Uniwersytecie Lubelskim Jana Pawła II. Idee, teorie, badania, red. W. Szymczak, TN KUL, Lublin 2018, s. 291-315 [współautor z W. Szymczak].

Religijna funkcja mowy ciała, „Civitas Christiana” 2018, nr 8-9, s. 35-36.

Przesądy Polaków a sacrum, „WPiS” 2018, nr 9, s. 74-78.

Władza ludzi słabych moralnie ma tragiczne skutki, „WPiS” 2018, nr 11, s. 10-14.

\section{9}

Socjologiczne rozumienie wartości $w$ aspekcie relacjonistycznym, „Zeszyty Naukowe KUL” 2019, t. 62, nr 3, s. 35-54.

W kręgu pychy. O krainie demiurgii i barbarii, „Arcana” 2019, nr 147, s. 21-34.

Formy i przejawy władzy mediów, w: Jednostka, społeczeństwo, państwo. Księga pamiątkowa ku czci śp. profesora Jerzego Rebety, red. A. Podraza, W. Gizicki, Wydawnictwo KUL, Lublin 2019, s. 197-212.

Na pasywność katolików liczą tęczowi, „WPiS” 2019, nr 9, s. 12-16.

Nie dajmy się zwodzić kłamcom i obłudnikom, „WPiS” 2019, nr 5, s. 33-38.

\section{0}

Jabłoński A., J. Szymczyk, Realist-Axiological Perspectives and Images of Social Life. A Century of Sociology at The John Paul II Catholic University of Lublin, Peter Lang, Berlin 2020, ss. 294.

O. Wacław Nowakowski (Edward z Sulgostowa), „Arcana” 2020, nr 154, s. 79-87.

Chrześcijanin w czasie zarazy, „WPiS” 2020, nr 5, s. 62-64.

Bieda pozamaterialna, „WPiS” 2020, nr 7-8, s. 25-28.

Rektorzy - obrońcy gender, „WPiS” 2020, nr 10, s. 21-24. 